Supporting Information

\title{
High-efficiency solar vapor generation boosted by solar-induced updraft with biomimetic 3D structures
}

Changwook Kim ${ }^{1}$, Dongheok Shin ${ }^{1}$, Monu Nath Baitha ${ }^{1}$, Yunha Ryu ${ }^{1}$, Augustine M. Urbas ${ }^{2}$, Wounjhang Park ${ }^{3}$ and Kyoungsik Kim ${ }^{1 *}$

${ }^{1}$ School of Mechanical Engineering, Yonsei University, 50 Yonsei-ro, Seodaemun-gu, Seoul 03722, Republic of Korea.

${ }^{2}$ Materials and Manufacturing Directorate, Air Force Research Laboratory, Wright-Patterson AFB, OH 45433, USA.

${ }^{3}$ Department of Electrical, Computer \& Energy Engineering, University of Colorado, Boulder, CO 80309, USA.

*E-mail: kks@yonsei.ac.kr 


\section{S1. Capillary penetration of the BPVA}

To make the evaporator into three dimensions with a height, water must be raised through capillary penetration. In an ideal situation where there is no gravity and no evaporation, the distance of water movement $h$ in the BPVA foam by the capillary effect is determined by the following formula

$$
h^{2}=\frac{4 \sigma \cos \theta_{s}}{\phi \mu} \frac{K}{R_{s}} t
$$

where $\sigma$ is the surface tension, $\theta_{s}$ is the contact angle between BPVA and water, $K$ and $\phi$ are the permeability and porosity of the BPVA, respectively, $\mu$ is the viscosity of the water, $R_{S}$ is the pore radius, $t$ is the time. ${ }^{1}$ Since the square of the distance is proportional to time, there is no limit to the distance the water extends. However, in the case of our 3D evaporation units, the maximum height that water can rise is limited due to the gravity and evaporation. When both gravity and evaporation are considered, the first-order differential equation for the water height is derived as follows

$$
\dot{h}=\frac{a}{h}-b-c h
$$

where the coefficients $a, b$, and $c$ are defined as

$$
\begin{gathered}
a=\frac{2 \sigma \cos \theta_{s}}{\phi \mu} \frac{K}{R_{s}} \\
b=\frac{\rho g K}{\phi \mu} \\
c=\frac{\dot{m}_{e}(W+T)}{\rho W T \phi}
\end{gathered}
$$

where $\rho$ is the density of water, $g$ is the gravitational acceleration, $\dot{m}_{e}$ is the evaporation rate, $W$ and $T$ are the width and thickness of the BPVA, respectively. We can obtain maximum heights of water by assuming $\dot{h}=0$ in eq $\mathrm{S} 2$ and the maximum height is calculated as

$$
h_{\max }=\frac{-b}{2 c}+\sqrt{\frac{b^{2}}{4 c^{2}}+\frac{a}{c}}
$$

As shown in Figure S1 a-c, we measured $\dot{h}$ at three different heights of BPVA and calculated $a, b$, and $c$ using eq S2. Using the values of $a, b, c$, and eq S6, the maximum height of water in BPVA was calculated, and the result is $h_{\max , B P V A, D a r k}=20.1 \mathrm{~cm}$. In addition, by adjusting the value of $c$ using the ratio of the evaporation rate under dark and 1-Sun condition, the maximum height under 1-Sun was obtained $\left(h_{\max , B P V A, 1 \text { Sun }}=17.5 \mathrm{~cm}\right)$. In this study, the evaporation units (EUs) are built lower than these heights $\left(h_{E U}=6.08 \mathrm{~cm}\right)$, so the water can reach the top of the EU. The maximum height of water of PVA without carbon coating $\left(h_{\text {max }, P V A, D a r k}=7.5 \mathrm{~cm}\right)$ was lower than that of BPVA (Figure S1 d-f). This result shows that carbon coating improves the wicking property. 
BPVA
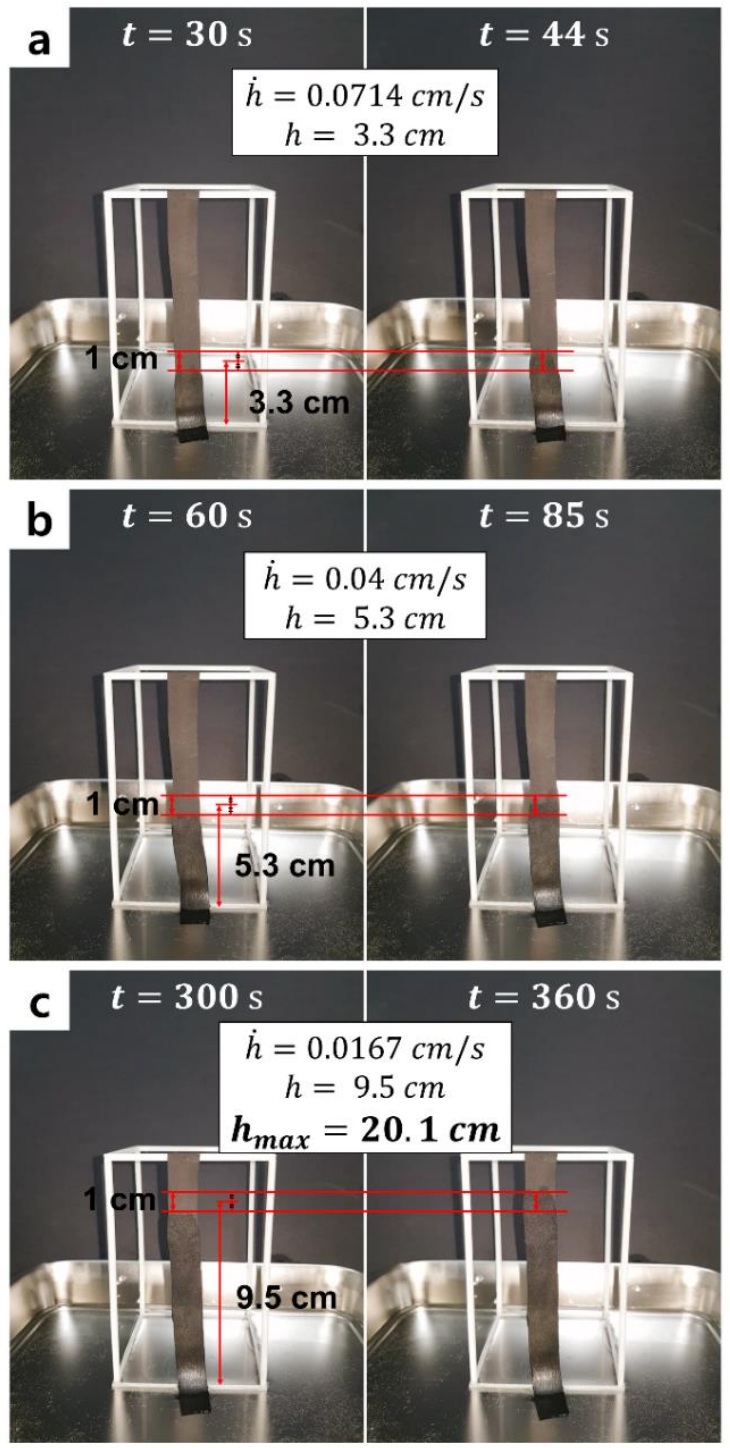

PVA
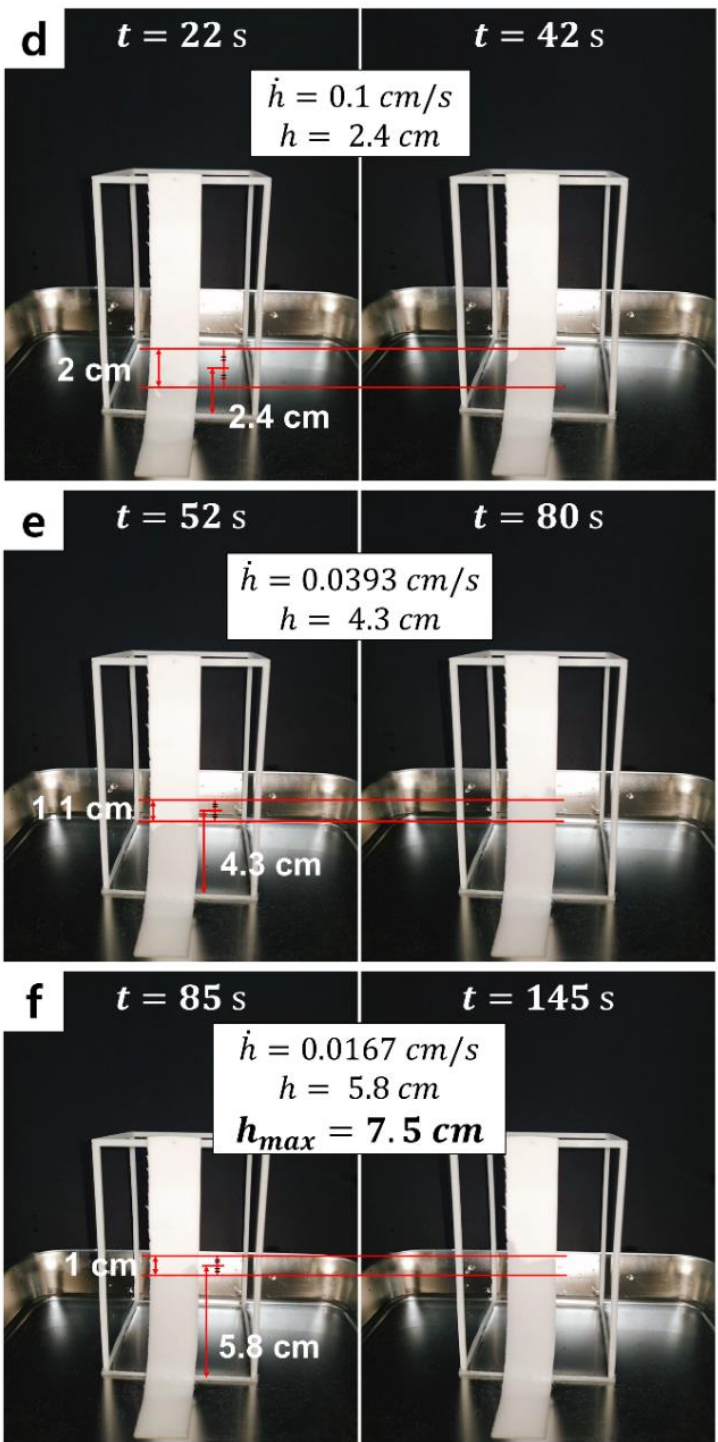

Figure S1. Capillary penetration test of BPVA and PVA. Photograph of BPVA (a) 30-44 s, (b) 60-85 s, (c) 300$360 \mathrm{~s}$ after contact with water. Photograph of PVA (d) 22-42 s, (e) 52-80 s, (f) 85-145 s after contact with water. 


\section{S2. Experimental results for all samples}

\begin{tabular}{|c|c|c|c|c|c|c|}
\hline Experiments & Sample No. & $\begin{array}{l}\text { Sample } \\
\text { condition }\end{array}$ & $\begin{array}{c}\text { Solar } \\
\text { illuminate } \\
\mathrm{d} \text { area } \\
\left(\mathrm{cm}^{2}\right) \\
\end{array}$ & $\begin{array}{l}\text { Evaporation } \\
\text { rate } \\
{\left[\mathrm{kg} \mathrm{m}^{-2} \mathrm{~h}^{-1}\right]}\end{array}$ & $\begin{array}{l}\text { Efficiency* } \\
{[\%]}\end{array}$ & $\begin{array}{c}\text { Efficiency } \\
\text { w/o Dark } \\
\text { [\%] }\end{array}$ \\
\hline \multirow{2}{*}{ 2D flat evaporator } & 1_D & 2D flat & 25.00 & 0.1847 & N/A & \multirow{2}{*}{43.4} \\
\hline & 1_S & 2D flat & 25.00 & 1.0496 & 52.7 & \\
\hline \multirow{8}{*}{$\begin{array}{l}\text { 3D evaporator with } \\
\text { various angles }\end{array}$} & 2_D & $30^{\circ}$ & 21.65 & 0.3189 & N/A & \multirow{2}{*}{57.6} \\
\hline & 2_S & $30^{\circ}$ & 21.65 & 1.4666 & 73.6 & \\
\hline & 3_D & $45^{\circ}$ & 17.68 & 0.4375 & N/A & \multirow{2}{*}{57.3} \\
\hline & 3_S & $45^{\circ}$ & 17.68 & 1.5795 & 79.3 & \\
\hline & 4_D & $60^{\circ}$ & 12.50 & 0.6660 & N/A & \multirow{2}{*}{59.8} \\
\hline & 4_S & $60^{\circ}$ & 12.50 & 1.8576 & 93.2 & \\
\hline & 5_D & $80^{\circ}$ & 4.34 & 1.8453 & N/A & \multirow{2}{*}{85.1} \\
\hline & 5_S & $80^{\circ}$ & 4.34 & 3.5405 & 177.7 & \\
\hline \multirow{6}{*}{$\begin{array}{l}\text { Gap difference between } \\
\text { two evaporator }\end{array}$} & 6_D & No gap & 8.68 & 1.2382 & N/A & \multirow{2}{*}{59.2} \\
\hline & 6_S & No gap & 8.68 & 2.4175 & 121.3 & \\
\hline & 7_D & $1 \mathrm{~cm}$ gap & 8.68 & 1.5763 & N/A & \multirow{2}{*}{65.9} \\
\hline & 7_S & $1 \mathrm{~cm}$ gap & 8.68 & 2.8887 & 145.0 & \\
\hline & 8_D & $2 \mathrm{~cm}$ gap & 8.68 & 1.6607 & N/A & \multirow{2}{*}{69.9} \\
\hline & 8_S & $2 \mathrm{~cm}$ gap & 8.68 & 3.0538 & 153.3 & \\
\hline \multirow{6}{*}{$\begin{array}{l}\text { Efficiency increasing by } \\
\text { updraft inspired by } \\
\text { Amorphophallus titanum }\end{array}$} & 9_D & 16/16 EUs & 23.04 & 1.0442 & N/A & \multirow{2}{*}{67.4} \\
\hline & 9_S & 16/16 EUs & 23.04 & 2.3868 & 119.8 & \\
\hline & 10_D & 12/16 EUs & 23.04 & 0.9667 & N/A & 760 \\
\hline & 10_S & 12/16 EUs & 23.04 & 2.4992 & 125.4 & 10.9 \\
\hline & 11_D & 8/9 EUs & 12.96 & 1.3419 & N/A & 853 \\
\hline & 11_S & 8/9 EUs & 12.96 & 3.0415 & 152.6 & 05.3 \\
\hline \multirow{4}{*}{$\begin{array}{l}\text { Updraft boosted by the } \\
\text { solar-chimney structure }\end{array}$} & 12_D & 9/9 EUs & 12.96 & 1.4305 & N/A & \multirow{2}{*}{70.9} \\
\hline & 12_S & 9/9 EUs & 12.96 & 2.8430 & 142.7 & \\
\hline & 13_D & $\begin{array}{c}8 / 9 \text { EUs } \\
\text { solar chimney }\end{array}$ & 12.96 & 1.3993 & N/A & \multirow{4}{*}{91.1} \\
\hline & 13_S & $\begin{array}{c}\text { 8/9 EUs } \\
\text { solar chimney }\end{array}$ & 12.96 & 3.3103 & 166.1 & \\
\hline \multirow{6}{*}{ Variable wind speeds } & 14_D & $1 \mathrm{~m} \mathrm{~s}^{-1}$ & 4.34 & 7.1756 & N/A & \\
\hline & 14_S & $1 \mathrm{~m} \mathrm{~s}^{-1}$ & 4.34 & 8.9902 & 451.2 & \\
\hline & 15_D & $2 \mathrm{~m} \mathrm{~s}^{-1}$ & 4.34 & 9.7814 & N/A & \multirow{2}{*}{112.9} \\
\hline & 15_S & $2 \mathrm{~m} \mathrm{~s}^{-1}$ & 4.34 & 12.0306 & 603.8 & \\
\hline & 16_D & $3 \mathrm{~m} \mathrm{~s}^{-1}$ & 4.34 & 13.6463 & N/A & \multirow{2}{*}{131.4} \\
\hline & 16_S & $3 \mathrm{~m} \mathrm{~s}^{-1}$ & 4.34 & 16.2642 & 816.3 & \\
\hline
\end{tabular}

Table S1. Experimental results for all samples. D: dark condition, S: solar condition, EU: evaporator unit. In sample No. D represents the experiment performed under dark conditions and S represents the experiment performed with solar illumination.

* Efficiency before subtracting evaporation rate under dark conditions. ** Efficiency after subtracting evaporation rate under dark conditions. 
a

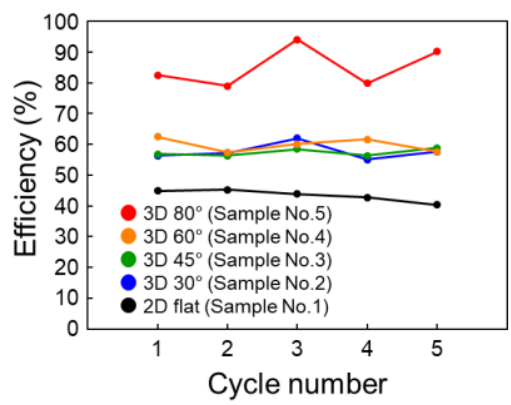

b

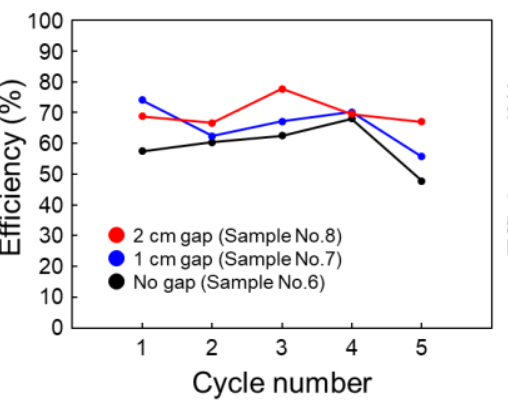

C

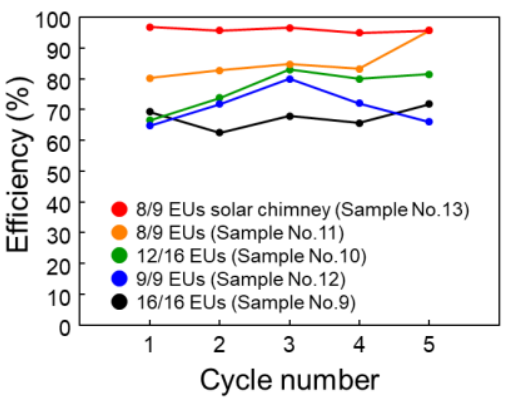

Figure S2. Efficiencies of the (a) 3D evaporators with various angles, (b) 3D evaporators with various distances, and (c) 3D evaporators inspired by Amorphophallus titanium and solar chimney during five experiments. 


\section{S3. Photos and IR images of all samples}

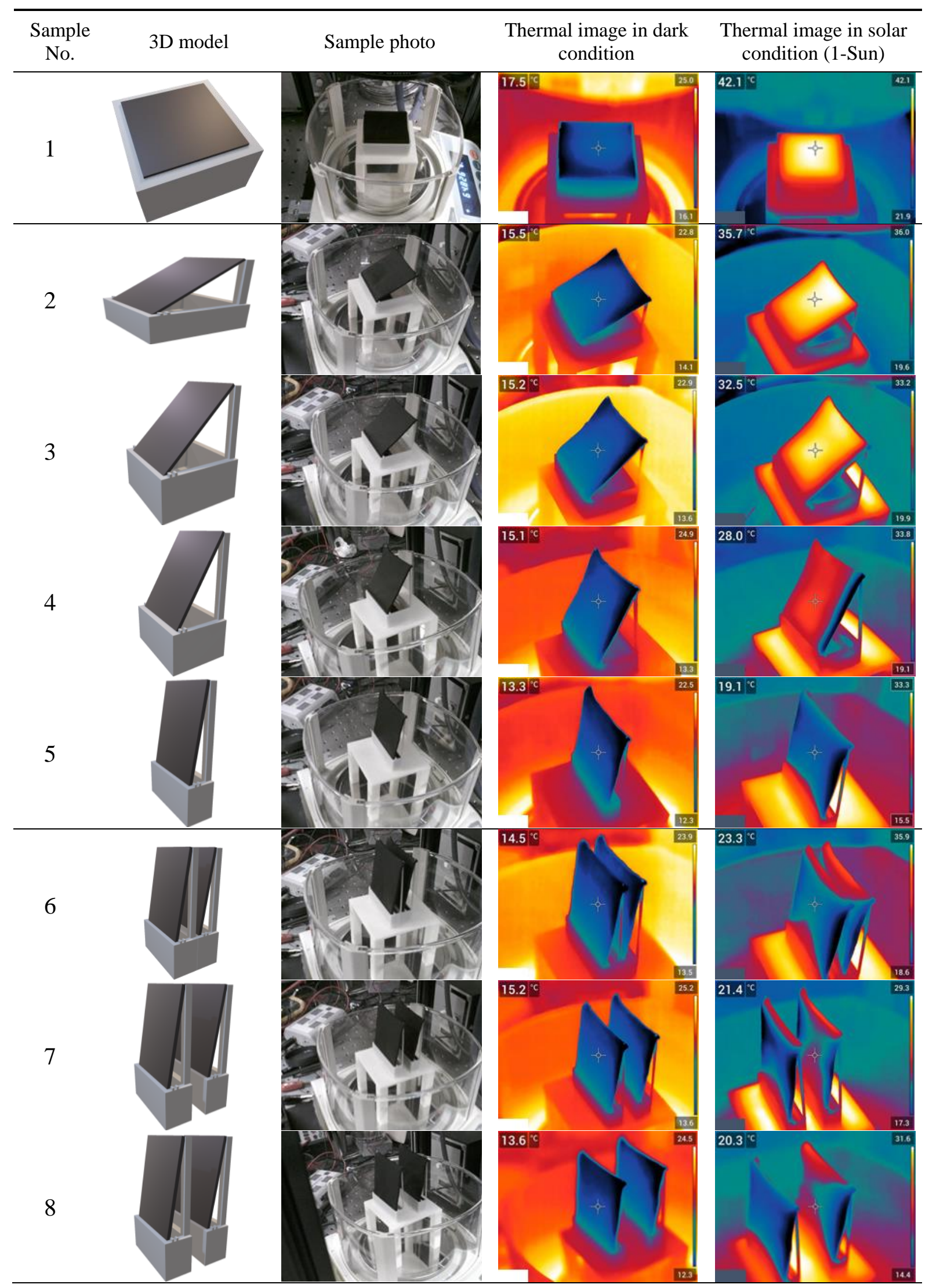




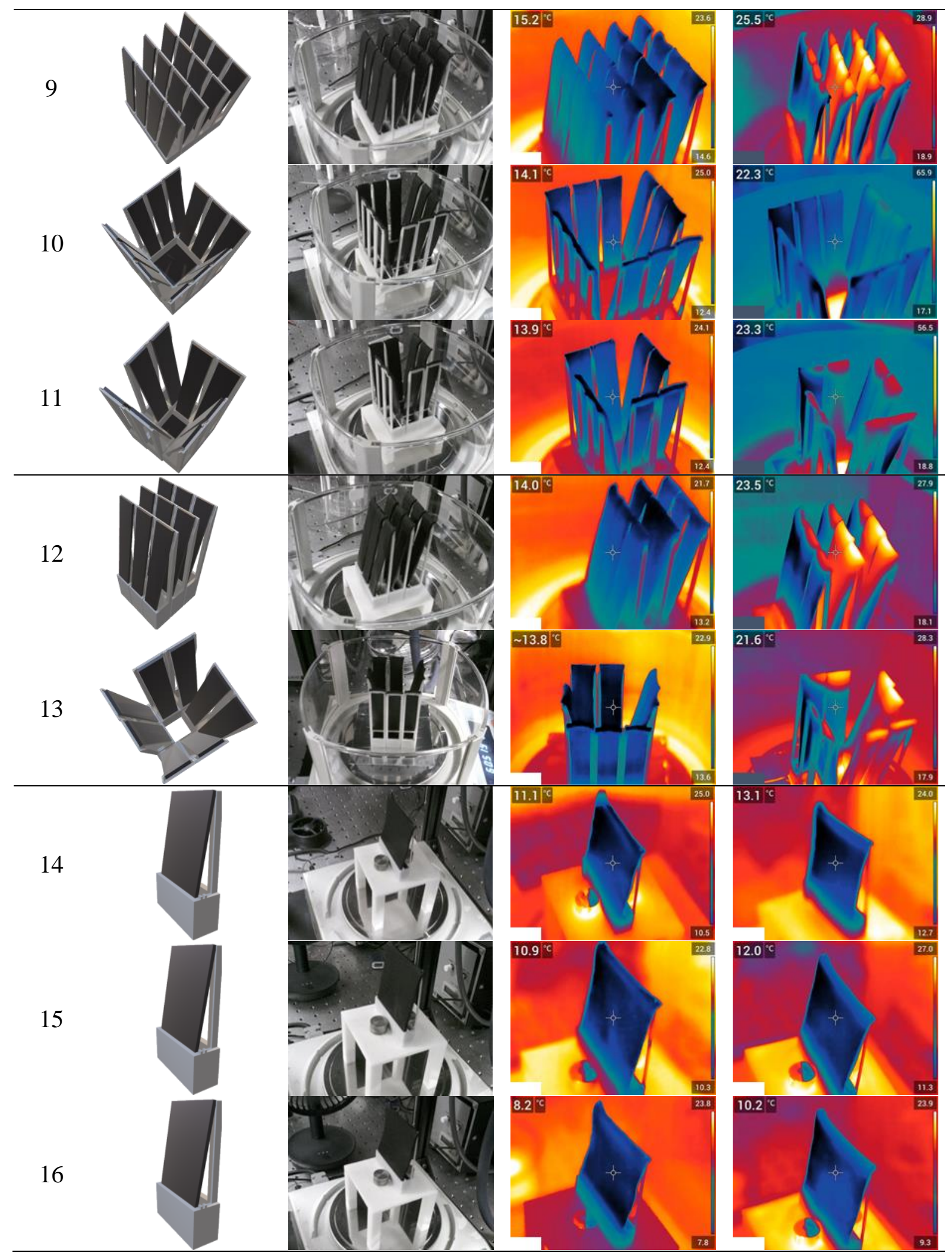

Table S2. Photos and IR images of all the samples. The left and right column of the IR images were taken under dark and 1-Sun conditions, respectively. 


\section{S4. Heat loss reduction by lowering surface temperature of the BPVA}

The temperatures of the 3D evaporators are lower than that of the 2D evaporators because the solar energy is diffused over a larger area than in 2D evaporator. This lowered temperature can minimize the heat loss. In our 3D evaporators, because the temperature differences between the BPVA surfaces and the ambient temperature are relatively small $\left(\Delta T<30{ }^{\circ} \mathrm{C}\right)$, most of the heat losses are caused by convection. The convective heat loss per unit solar irradiated area in a $3 \mathrm{D}$ evaporator is calculated by the following formula

$$
\dot{q}=\frac{h A_{\text {evap }}\left(T_{B P V A}-T_{0}\right)}{A_{\text {solar }}}
$$

where $h$ is the convective heat transfer coefficient, $A_{\text {evap }}$ is the evaporation area, $A_{\text {solar }}$ is the solar illuminated area, $T_{\mathrm{BPVA}}$ is the temperature of the BPVA surface, and $T_{0}$ is the ambient temperature $\left(20^{\circ} \mathrm{C}\right)$. For the simplicity, we assumed the $h$ as $5 \mathrm{~W} \mathrm{~m}^{-2} \mathrm{~K}^{-1}$ for all cases. Table S3 shows the calculated heat losses of the 2D, 3D evaporators, 8/9 EUs solar chimney, and other $3 \mathrm{D}$ EU configurations. In the $30^{\circ}, 45^{\circ}$, and $60^{\circ} 3 \mathrm{D}$ evaporators, the evaporation area increased significantly, while the temperature reduction was relatively small, so the heat losses were increased compared to the $2 \mathrm{D}$ evaporator. However, in the case of $80^{\circ} 3 \mathrm{D}$ evaporator, the heat loss is negative because the temperature of the evaporation area is lower than the ambient temperature even if solar power of 1-Sun is irradiated. The result means that the energy needed for evaporation can be derived not only from solar power but also from the thermal energy of the surrounding air. ${ }^{2}$ Even in our final model, 8/9 EUs solar chimney, the heat loss was calculated much smaller than 2D evaporator because the temperature was significantly reduced compared to the increased area.

\begin{tabular}{|c|c|c|c|c|c|c|}
\hline Sample & $\begin{array}{l}A_{\text {evap }} \\
{\left[\mathrm{cm}^{2}\right]}\end{array}$ & $\begin{array}{l}A_{\text {Solar }} \\
{\left[\mathrm{cm}^{2}\right]}\end{array}$ & $\begin{array}{c}T_{B P V A} \\
{\left[{ }^{\circ} \mathrm{C}\right]} \\
\end{array}$ & $\begin{array}{c}T_{0} \\
{\left[{ }^{\circ} \mathrm{C}\right]}\end{array}$ & $\begin{array}{c}h \\
{\left[\mathrm{~W} \mathrm{~m}^{-2} \mathrm{~K}^{-1}\right]}\end{array}$ & $\begin{array}{c}\text { Heat loss }(\dot{q}) \\
{\left[\mathrm{W} \mathrm{m}^{-2}\right]}\end{array}$ \\
\hline 2D flat & 25 & 25 & 42.1 & \multirow{6}{*}{20} & \multirow{6}{*}{5} & 110.5 \\
\hline $30^{\circ}$ & 50 & 21.65 & 35.7 & & & 181.3 \\
\hline $45^{\circ}$ & 50 & 17.68 & 32.5 & & & 176.8 \\
\hline $60^{\circ}$ & 50 & 12.50 & 28.0 & & & 160.0 \\
\hline $80^{\circ}$ & 50 & 4.34 & 19.1 & & & -51.8 \\
\hline $\begin{array}{c}\text { 8/9 EUs } \\
\text { solar chimney } \\
\end{array}$ & 132.7 & 12.96 & 21.6 & & & 81.9 \\
\hline $16 / 16$ EUs & 265.4 & 23.04 & 25.5 & \multirow{4}{*}{20} & \multirow{4}{*}{5} & 316.8 \\
\hline 12/16 EUs & 199.0 & 23.04 & 22.3 & & & 99.3 \\
\hline 8/9 EUs & 132.7 & 12.96 & 23.3 & & & 168.9 \\
\hline 9/9 EUs & 149.3 & 12.96 & 23.5 & & & 201.6 \\
\hline
\end{tabular}

Table S3. Calculated convective heat losses of the 2D, 3D evaporators, 8/9 EUs solar chimney, and other 3D EU configurations. 


\section{S5. Enthalpy of water evaporation from the BPVA surfaces.}

\begin{tabular}{|c|c|c|c|c|}
\hline $\begin{array}{c}\text { No. } \\
\text { (yy.mm.dd) }\end{array}$ & $\begin{array}{c}\text { Evaporation rate } \\
\text { of bulk water } \\
{\left[\mathrm{g} \mathrm{m}^{-2} \mathrm{~h}^{-1}\right]}\end{array}$ & $\begin{array}{c}\text { Evaporation rate } \\
\text { of BPVA } \\
{\left[\mathrm{g} \mathrm{m}^{-2} \mathrm{~h}^{-1}\right]}\end{array}$ & $\begin{array}{c}\text { Temperature / } \\
\text { humidity } \\
{\left[{ }^{\circ} \mathrm{C} / \%\right]}\end{array}$ & $\begin{array}{c}\text { Evaporation } \\
\text { ratio } \\
\text { (water/BPVA) }\end{array}$ \\
\hline 1. (19.04.26) & 105.232 & 136.996 & $25.1^{\circ} \mathrm{C} / 42 \%$ & 0.7681 \\
\hline 2. (19.04.27) & 96.332 & 132.884 & $23.7^{\circ} \mathrm{C} / 44 \%$ & 0.7249 \\
\hline 3. (19.04.28) & 94.712 & 133.168 & $21.3^{\circ} \mathrm{C} / 42 \%$ & 0.7112 \\
\hline 4. (19.05.29) & 153.228 & 194.416 & $28.1^{\circ} \mathrm{C} / 36 \%$ & 0.7881 \\
\hline 5. (19.05.30) & 127.532 & 183.54 & $27.1^{\circ} \mathrm{C} / 40 \%$ & 0.6948 \\
\hline
\end{tabular}

Table S4. Evaporation rate of bulk water and BPVA, taken on different days at the same time interval of $10 \mathrm{~h}$

Table S4 shows the evaporation rate of bulk water and BPVA, taken on different days at the same time interval of $10 \mathrm{~h}$ for better estimation of the reduced enthalpy of BPVA. The relationship between the enthalpy of bulk water and BPVA can be written as

$$
\dot{m}_{\text {water }} h_{\text {water }}=h_{B P V A} \dot{m}_{B P V A}
$$

where $\dot{m}_{\text {water }}$ and $\dot{m}_{B P V A}$ are the evaporation rate of bulk water and BPVA, $h_{\text {water }}$ and $h_{B P V A}$ are the enthalpy of bulk water and BPVA. ${ }^{3,4}$

The calculated reduced enthalpy of BPVA, $h_{B P V A}$, is $1806.8 \mathrm{~J} \mathrm{~g}^{-1}$ and $1789.8 \mathrm{~J} \mathrm{~g}^{-1}$ at $20{ }^{\circ} \mathrm{C}$ and $30{ }^{\circ} \mathrm{C}$, respectively, based on the above observation table. For this calculation of $h_{B P V A}$, we have used the reported value of $h_{\text {water }}\left(2450 \mathrm{~J} \mathrm{~g}^{-1}\right.$ at $20^{\circ} \mathrm{C}$ and $2427 \mathrm{~J} \mathrm{~g}^{-1}$ at $\left.30{ }^{\circ} \mathrm{C}\right)$. 


\section{S6. Updraft simulations of the structures mimicking convection flower (Amorphophallus titanum) and solar chimney}

We simulated the updraft generated by central hot-spot in the structure mimicking convection flower and the solar chimney. In both structures, the hotspot in the center creates an updraft. However, in the Amorphophallus titanum structure without air inlets, it is difficult to produce strong updraft. On the other hand, the Solar chimney structure with air inlets at the bottom generates stronger updraft.

a

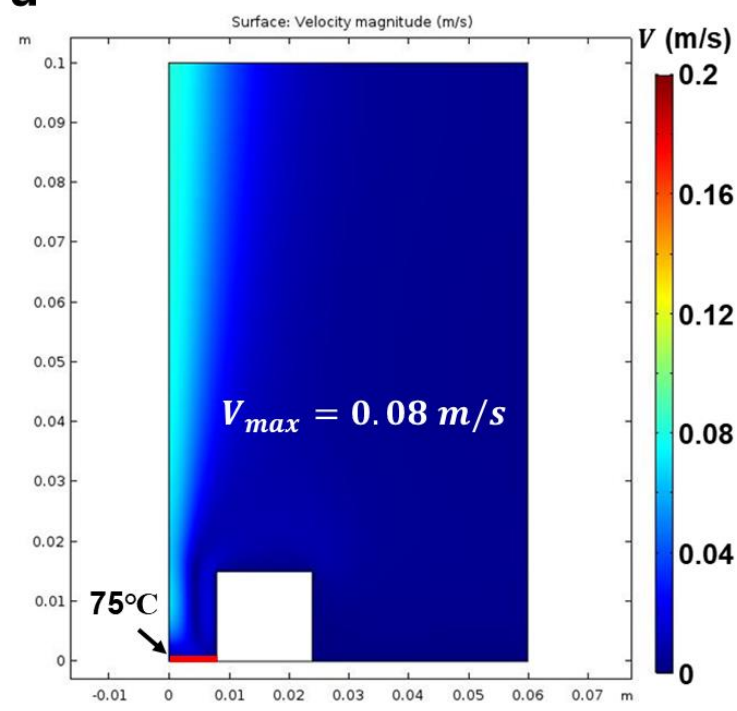

b

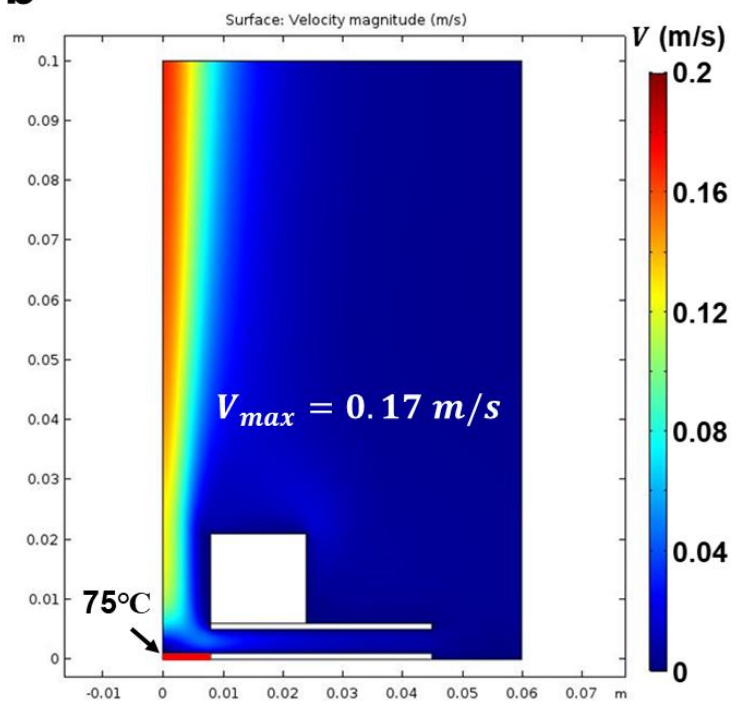

Figure S3. Simulation results for the cases of (a) Amorphophallus titanum and (b) solar chimney structure.

\section{Reference}

(1) Fries, N.; Odic, K.; Conrath, M.; Dreyer, M. The Effect of Evaporation on the Wicking of Liquids into a Metallic Weave. J. Colloid Interface Sci. 2008.

https://doi.org/10.1016/j.jcis.2008.01.019.

(2) Song, H.; Liu, Y.; Liu, Z.; Singer, M. H.; Li, C.; Cheney, A. R.; Ji, D.; Zhou, L.; Zhang, N.; Zeng, X.; et al. Cold Vapor Generation beyond the Input Solar Energy Limit. Adv. Sci. 2018, 5 (8), 1800222. https://doi.org/10.1002/advs.201800222.

(3) Zhao, F.; Zhou, X.; Shi, Y.; Qian, X.; Alexander, M.; Zhao, X.; Mendez, S.; Yang, R.; $\mathrm{Qu}, \mathrm{L}$.; Yu, G. Highly Efficient Solar Vapour Generation via Hierarchically Nanostructured Gels. Nat. Nanotechnol. 2018, 13 (6), 489-495. https://doi.org/10.1038/s41565-018-0097-z.

(4) Gong, F. (Frank); Li, H.; Wang, W.; Huang, J.; Xia, D. (David); Liao, J.; Wu, M.; Papavassiliou, D. V. Scalable, Eco-Friendly and Ultrafast Solar Steam Generators Based on One-Step Melamine-Derived Carbon Sponges toward Water Purification. Nano Energy 2019, 58, 322-330.

https://doi.org/https://doi.org/10.1016/j.nanoen.2019.01.044. 